\title{
Mössbauer Spectroscopic Study of Polymer-Bound Heme Complexes
}

\author{
Eishun TsuchidA, Hiroyuki Nishide, Hiroyuki YoKOYAMA, \\ Hidenari INOUE, ${ }^{*}$ and Tsuneo SHIRAI* \\ Department of Polymer Chemistry, Waseda University, \\ Shinjuku-ku, Tokyo 160, Japan \\ *Department of Applied Chemistry, Keio University, \\ Kohoku-ku, Yokohama 223, Japan
}

(Received December 14, 1983)

\begin{abstract}
Mössbauer spectra were measured on the heme complexes of poly(1-vinyl- and 1vinyl-2-methylimidazole) (PVI and PMI) and heme derivatives with covalently bound imidazoleligand $(\mathrm{IH})$ and 2-methylimidazole-ligand $(\mathrm{MIH})$ embedded in poly(1-vinyl-2-pyrrolidone) film. Quadrupole splitting $\left(\Delta E_{\mathrm{Q}}\right)$ for the carbon monoxide adduct of PMI-heme indicated large electronic field gradient at the iron nucleus, probably due to steric hindrance of the polymer chain, and this behavior agreed with its low affinity with carbon monoxide. PMI-heme formed an oxygen adduct and its isomer shift and $\Delta E_{\mathrm{Q}}$ values were obtained.
\end{abstract}

KEY WORDS Poly(1-vinyl-2-methylimidazole) / Iron(II) Protoporphyrin IX / Mössbauer Spectra / Polymer Complex / Hemoglobin Model /

Much effort has been made to mimic natural oxygen carriers like hemoglobin by using modified synthetic iron-porphyrin complexes. ${ }^{1-4}$ In one approach, a series of heme derivatives with covalently bound imidazole ligands have been synthesized and well studied by Traylor. $^{2,5}$ The mesoheme-mono- $N$-[3-(1imidazolyl) propyl]amide monomethyl ester is a typical compound which forms an oxygen adduct in aprotic, organic solvents. The advanced study of this approach is to attach an iron-porphyrin complex to a synthetic polymer. ${ }^{6,7}$ The authors have recently found that poly(1-vinyl-2-methylimidazole) (PMI)-ironprotoporphyrin IX (heme) ${ }^{8}$ and poly(1-vinyl2-pyrrolidone)-bound protoheme-mono- $N$-[3(1-imidazolyl)-propyl]amide and -mono- $N$-[5(2-methyl-1-imidazolyl) pentyl]amide ${ }^{9,10}$ form oxygen adducts not only in organic solvents but also in a cooled aqueous medium. The requisites for oxygen binding in aqueous medium are considered to be that a pentacoor- dinate heme complex, whose sixth coordination site is vacant to bind oxygen, is immobilized by a polymer and surrounded by hydrophobic environment of the polymer.

Electronic structure of the iron ion in hemoproteins and heme complexes has been studied with Mössbauer spectroscopy. Mössbauer spectra of several iron-porphyrin compounds have been already reported, ${ }^{11-14}$ but no reports have been found for the heme complex ligated with 2-methylimidazole, which preferentially had the pentacoordinate structure, and for the polymer-bound heme. In this paper, Mössbauer measurement was carried out on the deoxy complexes, carbon monoxide and oxygen adducts of the heme complexes of poly(1-vinyl- and 1-vinyl-2methylimidazole) (PVI and PMI) and the heme derivatives with covalently bound imidazole-ligand (IH) and 2-methylimidazoleligand (MIH) embedded in poly(1-vinyl-2pyrrolidone) (PVP) film (Scheme 1). The ob- 


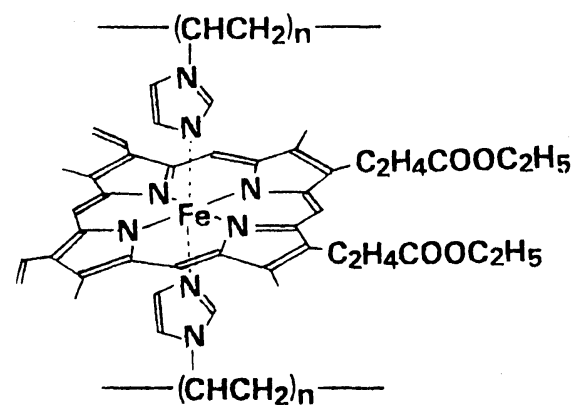

PVI-heme

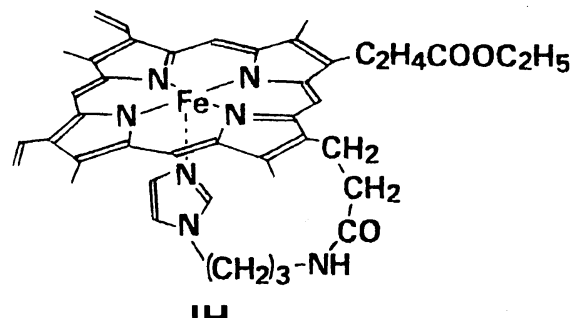

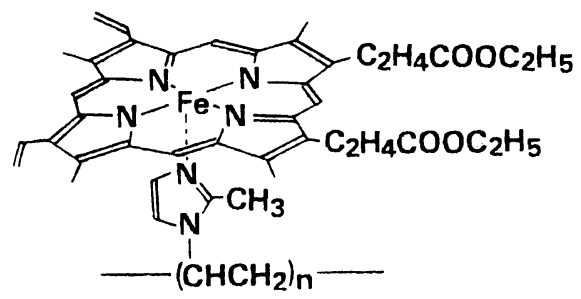

PMI-heme

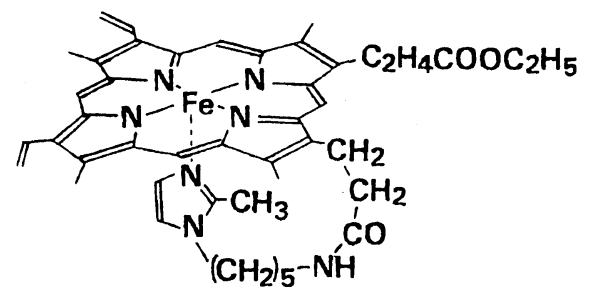

MIH

Scheme 1.

tained isomer shift $(\delta)$ and quadruple splitting $\left(\Delta E_{\mathrm{Q}}\right)$ were compared with those of the corresponding imidazole-heme complexes, and the effect of polymer on the electronic structure of the heme complex was discussed.

\section{EXPERIMENTAL}

\section{Materials}

Poly(1-vinylimidazole) (PVI) and poly(1vinyl-2-methylimidazole) (PMI) were prepared as follows. 1-Vinylimidazole $(32.9 \mathrm{~g}, 0.35 \mathrm{~mol})$ was polymerized with 2,2 '-azobisisobutyronitrile $(1.01 \mathrm{~g}, 7.4 \mathrm{mmol})$ in methanol $(160 \mathrm{ml})$ at $80^{\circ} \mathrm{C}$ for $2 \mathrm{~h}$. The obtained polymer was purified by precipitating to diethyl ether repeatedly. Molecular weight of the polymer was measured by vapor pressure osmometry $\left(6.0 \times 10^{4}\right)$. 1-Vinyl-2-methylimidazole was polymerized in a similar manner as above $\left(\right.$ mol weight $\left.=4.5 \times 10^{4}\right)$.

Protoporphyrin IX diethyl ester was synthesized according to the procedure in lit. ${ }^{10}$
${ }^{57} \mathrm{Fe}(\mathrm{AcO})_{2}$ was prepared from ${ }^{57} \mathrm{Fe}_{2} \mathrm{O}_{3}$ according to the procedure in lit. ${ }^{15}$ Protoporphyrin IX diethyl ester $(60 \mathrm{mg}, 0.096 \mathrm{mmol})$ and ${ }^{57} \mathrm{Fe}(\mathrm{AcO})_{2}(31 \mathrm{mg}, 0.178 \mathrm{mmol})$ were dissolved in glacial acetic acid $(10 \mathrm{ml})$, and the mixture was refluxed under nitrogen for $10 \mathrm{~min}$. The solvent was removed by evaporation, and the residue was extracted with chloroform. The crude product was purified by chromatography on a basic alumina column $(1 \mathrm{~cm} \times 7 \mathrm{~cm})$ with chloroform. The first and the second fractions (iron(III) acetate and $\mu$-oxo dimer) were collected and washed with $5 \%$ hydrochloric acid and with water and dried $\left(\mathrm{Na}_{2} \mathrm{SO}_{4}\right)$, and then the solvent was removed by evaporation. The ultraviolet and visible spectra characterized by absorptions at $406,504,539,574,628,669 \mathrm{~nm}$ of protoporphyrin IX diethyl ester changed to those at $402,505,537,632 \mathrm{~nm}$ of $\mathrm{Fe}(\mathrm{III})$ protoporphyrin IX diethyl ester chloride.

Protoporphyrin IX mono- $N$-[3-(1-imidazolyl) propyl]amide and -mono- $N$-[5-(2- 
methyl-1-imidazolyl) pentyl]amide were synthesized according to the procedure in lit..$^{10,16}$ The incorporation of the iron in these porphyrins was carried out in a similar manner as above.

Imidazole and 2-methylimidazole were recrystallized from benzene. Poly(1-vinyl-2pyrrolidone) $(\mathrm{PVP})\left(\mathrm{mol}\right.$ weight $\left.=4 \times 10^{4}\right)$ was purified by reprecipitating in acetone.

\section{Preparation of Film of the Heme Complexes}

$\mathrm{Fe}(\mathrm{III})$ protoporphyrin IX diethyl ester and the polymeric ligand (PVI or PMI) were dissolved in $N, N$-dimethylformamide (DMF). Nitrogen gas was bubbled through the solution and a small amount of aqueous sodium dithionite $\left(\left[\mathrm{Na}_{2} \mathrm{~S}_{2} \mathrm{O}_{4}\right] /[\mathrm{Fe}]=5\right)$ was added to obtain the $\mathrm{Fe}$ (II) complex solution. The carbon monoxide adduct was prepared by bubbling carbon monoxide gas through this solution for $10 \mathrm{~min}$. The oxygen adduct was prepared by bubbling oxygen gas carefully after the solution was cooled at $-60^{\circ} \mathrm{C}$. The formation of each complex was confirmed spectroscopically; deoxy: $557 \mathrm{~nm}, \mathrm{CO}$ adduct: $538,566 \mathrm{~nm}$, $\mathrm{O}_{2}$ adduct: $545,577 \mathrm{~nm}$. These solutions were evaporated to dryness, yielding red and transparent films. The films of IH, MIH, the heme complex of imidazole and of 2-methylimidazole were similarly prepared by using poly(1-viny-2-pyrrolidone) as a polymer matrix.

\section{Mössbauer Spectroscopic Measurement}

The spectrometer was of the constantacceleration type. The source was used at room temperature and consisted of about $10 \mathrm{mCi}$ of ${ }^{57} \mathrm{Co}$ diffused in palladium foil. The absorbers with a thickness of about $0.2 \mathrm{mg}$ of iron per $\mathrm{cm}^{2}$ were kept at $77 \mathrm{~K}$. The Doppler velocity was calibrated with natural iron foil kept at room temperature and zero velocity was taken as the centroid of its Mössbauer spectrum at room temperature. The spectra were fitted to Lorentzian lineshapes by using the least-squares fitting program. Statistical uncertainties were $\pm 0.01 \mathrm{~mm} \mathrm{~s}^{-1}$ for all
Mössbauer parameters.

\section{Visible Spectroscopic Measurement}

Visible absorption spectra of the hemecontaining film were measured with a Hitachi UV-320 spectrophotometer. The heme complex solution was spectrophotometrically titrated with carbon monoxide; the formation constant $(K)$ of the $\mathrm{CO}$ adduct was calculated from the midpoint of the titration curve.

\section{RESULTS AND DISCUSSION}

Typical examples of Mössbauer spectra for the deoxy heme complexes are shown in Figure 1. The polymer-bound and the polymerembedded heme complexes were relatively stable in air and were easy to handle during the spectroscopic measurement.

Mössbauer parameters, the isomer shift $(\delta)$ and quadrupole splitting $\left(\Delta E_{\mathrm{Q}}\right)$, of the deoxy heme complexes obtained at $77 \mathrm{~K}$ are summarized in Table I. The small $\delta$ and $\Delta E_{\mathrm{Q}}$ values for the imidazole-ligated hemes, PVI-heme and imidazole-heme, indicated the iron ion being in ferrous low-spin state, while the large $\delta$ and $\Delta E_{\mathrm{Q}}$ values for the 2-methylimidazoleligated hemes, PMI-heme, MIH, and 2methylimidazole-heme, showed the iron ion in ferrous high-spin state. This result agrees with the composition of the heme complexes, i.e., bis(imidazole)-ligated heme and mono(2methylimidazole)-ligated heme, determined by spectrophotometric titration. ${ }^{17}$ The parameters of PVI-heme and PMI-heme were consistent with those of the corresponding monomeric heme complexes, and no difference between the polymer-bound and non-bound heme complex was observed in the parameters of ferrous deoxy state.

The $\delta$ value for IH and MIH hemes bound covalently with imidazole were larger than those for the others, suggesting that the fixation of the imidazole ligand with spacer groups caused the iron-imidazole bond to weaken. This result agreed with the NMR 


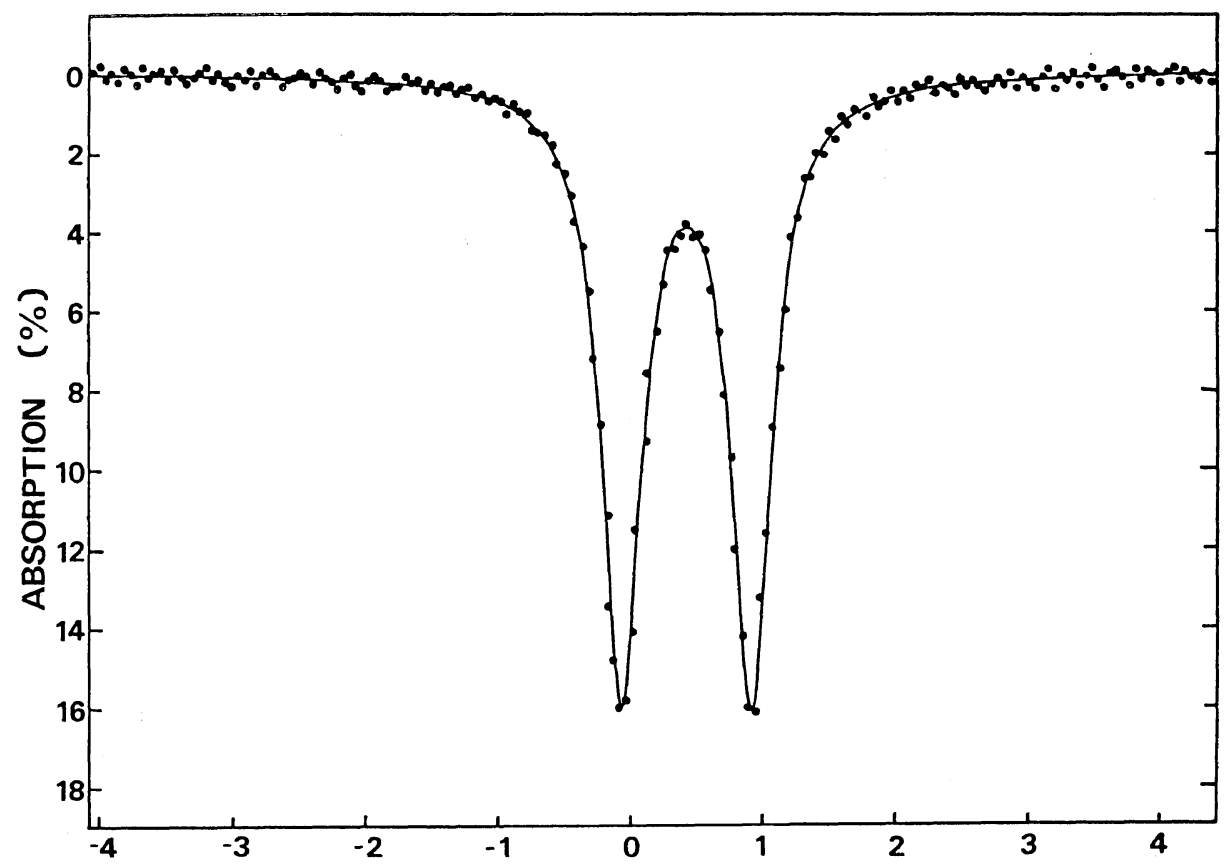

(a)

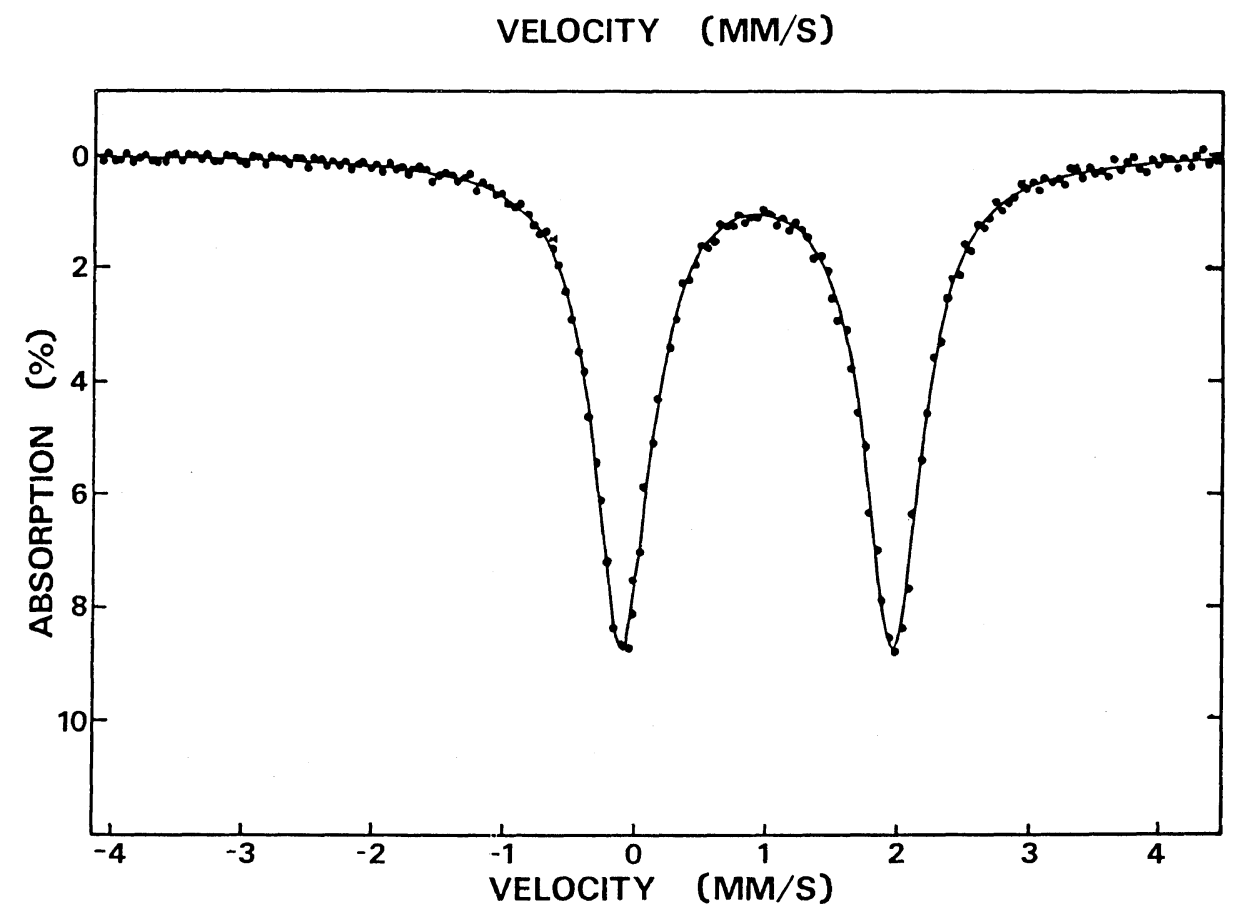

(b)

Figure 1. Mössbauer spectra of the deoxy heme complexes of PVI-heme (a) and MIH/PVP (b) at $77 \mathrm{~K}$. 
Table I. Mössbauer parameters of deoxy complexes $(77 \mathrm{~K})$

\begin{tabular}{lccc}
\hline \multirow{2}{*}{ Compounds } & \multicolumn{1}{c}{$\delta$} & & \multicolumn{1}{c}{$\Delta E_{\mathrm{Q}}$} \\
\cline { 2 - 2 } & $\mathrm{mm} \mathrm{s}^{-1}$ & $\mathrm{~mm} \mathrm{~s}^{-1}$ \\
\hline PVI-heme & 0.44 & 0.99 \\
PMI-heme & 0.89 & & 2.02 \\
IH/PVP & 0.95 & & 2.06 \\
MIH/PVP & 0.93 & 2.05 \\
Imidazole-heme/PVP & 0.44 & 0.98 \\
2-Methylimidazole-heme/PVP & 0.89 & 2.06 \\
\hline
\end{tabular}

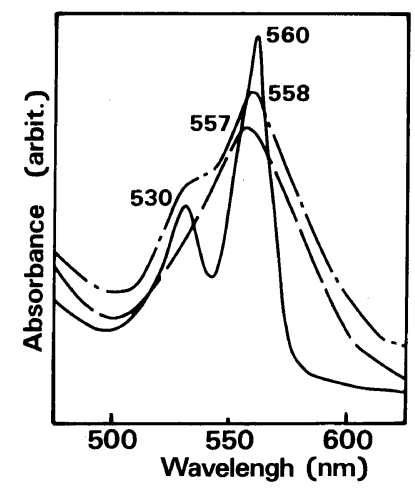

Figure 2. Visible spectra of the deoxy heme complexes in film. (-), PVI-heme; (---), IH/PVP; (---), PMIheme.

study on the heme derivatives with covalentlybound imidazole ligands which showed a strain in the iron-imidazole bond. ${ }^{18,19}$ The large $\Delta E_{\mathrm{Q}}$ values also suggested that charge distributions around the iron nucleus for $\mathrm{IH}$ and MIH were more aspherical.

Figure 2 shows the visible absorption spectra of the film-embedded heme complexes. PVI-heme and imidazole-heme gave the absorption spectrum with a double peak at 530 and $560 \mathrm{~nm}$ assigned to a hexacoordinate heme complex. On the other hand, the visible spectra of PMI-heme, 2-methylimidazole-heme, and MIH were characterized by a single peak absorption at $557 \mathrm{~nm}$, which was assigned to a pentacoordinate heme complex. IH showed a single peak $(558 \mathrm{~nm})$ spectrum with shoulder at $530 \mathrm{~nm}$. This spectrum suggested that a solvent molecule combined with the sixth coordination site of heme. ${ }^{5,10}$ However, the Mössbauer parameters ( $\delta$ and $\Delta E_{\mathrm{Q}}$ ) of IH in Table I were much larger than those of PVIheme and imidazole-heme, which meant that IH contained a high-spin iron ion. This result suggested that the iron ion of IH was pulled up from the porphyrin plane and $\mathrm{IH}$ had a square pyramidal structure like 2-methylimidazoleheme and hemoglobin, although $\mathrm{IH}$ had the imidazole ligand.

A typical example of Mössbauer spectra for the carbon monoxide adducts is shown in Figure 3 and their parameters in Table II. $\delta$ and $\Delta E_{\mathrm{Q}}$ were smaller than those of the bis(imidazole)-ligated heme complexes in Table I, due to the $\pi$-back donation to the coordinated carbon monoxide. $\delta$ values of carbon monoxide adducts of the 2methylimidazole-ligated hemes were larger than those of the imidazole-ligated hemes. This result demonstrated that the steric hindered 2-methyl group of the heme complexes pulled up the iron ion and the contribution of the $\pi$-back donation decreased with smaller $\sigma$ donation from the carbon monoxide. Formation constants $(K)$ for the carbon monoxide adducts are listed in the right column of Table II. The $K$ values of the 2methylimidazole-ligated hemes were about $10-10^{2}$ times smaller than those of the imidazole-ligated hemes; this agreed with the result obtained from the Mössbauer parameters. The $\Delta E_{\mathrm{Q}}$ values of the 2-methylimidazole-ligated hemes were relatively large because of a steric hindrance between the 2methyl group and the porphyrin plane. Especially, PMI-heme gave much larger $\Delta E_{\mathrm{Q}}$ value. Steric hindrance between the polymer chain and the porphyrin plane might probably cause a large electronic field gradient at the iron nucleus.

The Mössbauer parameters of the oxygen adducts are shown in Table III. Only deoxy PMI-heme formed the oxygen adduct (545, $577 \mathrm{~nm})$ on exposure to oxygen: This was 


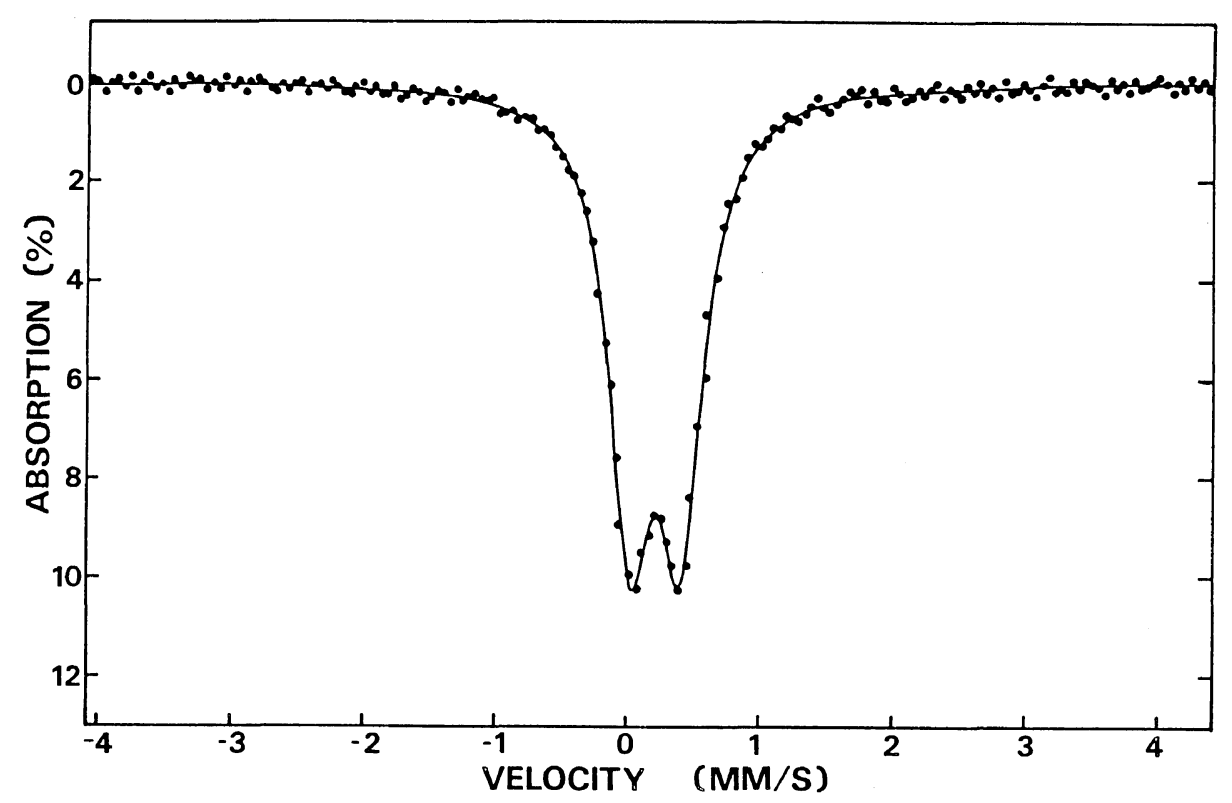

Figure 3. Mössbauer spectrum of the $\mathrm{CO}$ adduct of PMI-heme at $77 \mathrm{~K}$.

Table II. Mössbauer parameters of the carbon monoxide adducts ${ }^{\mathrm{a}}$ and formation constants $(K)$

\begin{tabular}{|c|c|c|c|}
\hline \multirow{2}{*}{ Compounds } & $\delta$ & $\Delta E_{\mathrm{Q}}$ & $K \times 10^{-5}$ \\
\hline & $\mathrm{mm} \mathrm{s}^{-1}$ & $\mathrm{~mm} \mathrm{~s}^{-1}$ & $1 \mathrm{~mol}^{-1}$ \\
\hline PVI-heme & 0.25 & 0.38 & - \\
\hline PMI-heme & 0.27 & 0.58 & $4.0^{\mathrm{b}}$ \\
\hline IH/PVP & 0.22 & 0.38 & $210^{\mathrm{c}}$ \\
\hline $\mathrm{MIH} / \mathrm{PVP}$ & 0.26 & 0.49 & $6.2^{\mathrm{c}}$ \\
\hline Imidazole-heme/PVP & 0.23 & 0.33 & - \\
\hline $\begin{array}{l}\text { 2-Methylimidazole- } \\
\text { heme/PVP }\end{array}$ & 0.25 & 0.51 & $11^{\mathrm{c}}$ \\
\hline
\end{tabular}

a Values at $77 \mathrm{~K}$.

b $\mathrm{pH} 10$ buffer solution at $20^{\circ} \mathrm{C}$.

c In $2 \%$ cetylpyridinium chloride solution, $\mathrm{pH} 10$ buffer at $20^{\circ} \mathrm{C}$.

similar to the previously reported result that the PMI-heme formed much more stable oxygen adduct in cooled DMF solution in comparison with 2-methylimidazole-heme and $\mathrm{MIH} .{ }^{20}$ It was considered that the vacant sixth coordination site of heme was necessary for the oxygen adduct formation and the polymer matrix was effective to protect the oxygen
Table III. Mössbauer parameters of the oxygen adducts

\begin{tabular}{|c|c|c|c|}
\hline \multirow{2}{*}{ Compound } & Temp & $\delta$ & $\Delta E_{\mathrm{Q}}$ \\
\hline & $\mathrm{K}$ & $\mathrm{mm} \mathrm{s}^{-1}$ & $\mathrm{~mm} \mathrm{~s}^{-1}$ \\
\hline PMI-heme & 100 & 0.25 & 2.15 \\
\hline FePFP $^{a}$ & 77 & 0.28 & 2.00 \\
\hline FePFP & 195 & 0.25 & 1.34 \\
\hline $\mathrm{Hb}^{\mathrm{b}}$ & 77 & 0.26 & 2.19 \\
\hline \multicolumn{4}{|c|}{$\begin{array}{l}\text { meso-Tetra }(\alpha, \alpha, \alpha, \alpha-(o \text {-pivalamidophenyl))-porphina } \\
\text { iron(II) complex of } 1 \text {-methylimidazole. Taken from } \\
21 .\end{array}$} \\
\hline
\end{tabular}

adduct from the irreversible oxidation via $\mu$ dioxodimer formation and/or from the proton-driven oxidation. The parameters were comparable with those of oxyhemoglobin and the oxygen adduct of iron picket fence porphyrin as previously reported, ${ }^{21,22}$ this meant that the iron ion in the oxygen adduct was in ferric low-spin state also for the polymerbound heme.

Acknowledgement. This work was partially 
supported by a Grant-in-Aid for Scientific Research from the Ministry of Education, Science and Culture, Japan.

\section{REFERENCES}

1. R. D. Jones, D. A. Summerville, and F. Basolo, Chem. Rev., 79, 139 (1979).

2. T. G. Traylor and P. S. Traylor, Ann. Rev. Biophys. Bioeng., 11, 105 (1982).

3. J. P. Collman, Acc. Chem. Res., 10, 265 (1977).

4. C. K. Chang, B. Ward, and C. B. Wang, J. Am. Chem. Soc., 103, 5236 (1981) and references therein.

5. C. K. Chang and T. G. Traylor, J. Am. Chem. Soc., 95, 8475, 8477 (1973); Proc. Natl. Acad. Sci. U.S.A., 72, 1166 (1975).

6. E. Tsuchida, J. Macromol. Sci., Chem., 13, 545 (1979).

7. K. Shigehara, K. Shinohara, Y. Sato, and E. Tsuchida, Macromolecules, 14, 1153 (1981).

8. H. Nishide, H. Ohno, and E. Tsuchida, Makromol. Chem., Rapid Commun., 2, 55 (1981).

9. E. Tsuchida, H. Nishide, and Y. Sato, J. Chem. Soc., Chem. Commun., 556 (1982).
10. E. Tsuchida, H. Nishide, Y. Sato, and M. Kaneda, Bull. Chem. Soc. Jpn., 55, 1890 (1982).

11. C. E. Johnson, "Mössbauer Spectroscopy," U. Gonser, Ed., Springer, Berlin, 1975, p 139.

12. J. R. Sams and T. B. Tsin, "The Porphyrins," D. Dorphin, Ed., New York, 1979, p 379.

13. Y. Maeda, J. Phys. (Paris) Colloq., 40, 514 (1979).

14. J. E. Falk, "Porphyrin and Metalloporphyrin," Elsevier, Amsterdam, 1964.

15. O. Warburg and E. Negelein, Biochem. Z., 244, 9 (1932).

16. J. Geibel, J. Cannon, D. Campbell, and T. G. Traylor, J. Am. Chem. Soc., 100, 3575 (1978).

17. E. Tsuchida, H. Nishide, and H. Ohno, J. Inorg. Biochem., 17, 283 (1982).

18. H. Goff, J. Am. Chem. Soc., 102, 3252 (1980).

19. F. A. Walker, J. Am. Chem. Soc., 102, 3254 (1980).

20. H. Nishide, M. Sekine, and E. Tsuchida, Polym. J., 14, 629 (1982).

21. G. Lang and W. Marshall, Proc. Phys. Soc., London, 87, 3 (1966).

22. J. P. Collman, R. R. Gagne, C. A. Reed, T. R. Halbert, G. Lang, and W. T. Robinson, J. Am. Chem. Soc., 97, 1427 (1975). 